\title{
Analisis Faktor Demografi yang Berhubungan dengan Distres Pasien Rawat Inap Diabetes Tipe II di Yogyakarta
}

\author{
Raisa Farida Kafil
}

\begin{abstract}
The high expectations and tightness of the diabetes therapy regimen is one of the biggest causes of distress in DM patients who are characterized by feelings of despair, worry about financing treatment, frustration due to uncontrolled blood glucose and blood pressure, and fear of the threat of further complications from DM. The aim of this study was to identify the demographic characteristics associated with distress in type 2 diabetes patients in Yogyakarta. There are five demographic factors identified as independent variables in this study including age, gender, education level, duration of diabetes and comorbidities. The results showed that most diabetic patients experienced mild distress (68.8\%), moderate $(31.3 \%)$, and severe $(0 \%)$. The most associated factor with diabetes distress is the level of education [ $p=0.039 ; 95 \%$ confidence interval $(\mathrm{Cl}): 0.464-9.889]$ Patients with lower levels of education have a risk of 2,143 times having diabetes distress [Exp (B): 2,143)].
\end{abstract}

Keyword: Demographic, Diabetes, Distress

\section{Intisari}

Tingginya harapan maupun ketatnya regimen terapi diabetes menjadi salah satu penyebab terbesar munculnya distress pada pasien DM yang ditandai perasaan putus asa, cemas akan akan pembiayaan pengobatan, perasaan frustasi akibat glukosa darah dan tekanan darah yang tidak terkontrol, serta takut akan ancaman terjadinya komplikasi lanjutan dari DM. Tujuan dari penelitian ini adalah untuk mengidentifikasi faktor karakteristik demografi yang berhubungan dengan distress pada pasien diabetes tipe 2 di Yogyakarta. Terdapat lima faktor demografi yang diidentifikasi peneliti sebagai variabel bebas dalam penelitian ini meliputi usia, jenis kelamin, tingkat pendidikan, lama menderita diabetes serta ada tidaknya komorbid diabetes. Hasil penelitian menunjukkan bahwa sebagian besar pasien diabetes mengalami distress ringan $(68,8 \%)$, sedang $(31,3 \%)$, dan berat $(0 \%)$. Faktor yang paling berhubungan dengan diabetes distres adalah tingkat pendidikan [ $p=0,039 ; 95 \%$ confidence interval $(\mathrm{Cl}): 0,464-9,898]$. Pasien dengan tingkat pendidikan yang lebih rendah berisiko 2,143 kali mengalami diabetes distress [Exp(B): 2,143)].

Kata kunci: Demografi, Diabetes, Distres

\section{Afiliasi Penulis}

Universitas ‘Aisyiyah Yogyakarta

Korespondensi kepada

R.F. Kafil

raisakafil@unisayogya.ac.id 


\section{Pendahuluan}

Diabetes mellitus (DM) tipe 2 merupakan salah satu masalah kesehatan yang memerlukan perhatian di masyarakat. Prevalensi DM meningkat secara signifikan di beberapa negara di dunia ${ }^{1}$. World Health Organization pada tahun 2017 menyatakan bahwa prevalensi DM secara global meningkat dari 108 juta individu pada tahun 1980 meningkat menjadi 422 juta individu pada tahun 2014. Selain itu, peningkatan prevalensi ini bukan hanya ditemui di tatanan global, namun juga pada tatanan nasional. Berdasarkan Riset Kesehatan Dasar (RISKESDAS) ${ }^{2}$ terdapat peningkatan prevalensi DM dari 1,1\% pada tahun 2007 menjadi $2,1 \%$ pada tahun 2013. Diabetes terdiagnosis dokter atau gejala sebesar 2,1 persen, dimana DI Yogyakarta memegang prevalensi diabetes yang tertinggi dengan angka prevalensi sebesar 2,6\%, disusul oleh DKI Jakarta (2,5\%), Sulawesi Utara $(2,4 \%)$ dan Kalimantan Timur (2,3\%).

Diagnosis DM yang dijatuhkan pada pasien memberikan dampak tersendiri yang mengarah pada kondisi yang menyebabkan stress serta membutuhkan strategi koping baik fisik maupun mental $^{3}$. Individu dengan diabetes sering kali dihadapkan dengan berbagai macam tantangan, misalnya keharusan untuk menjalani regimen terapi dan manajemen diri yang dilakukan sepanjang hidupnya ${ }^{4}$.

Pasien diabetes juga dihadapkan dengan pentingnya pencegahan, pengelolaan komplikasi diabetes yang mungkin muncul, serta masalahmasalah yang berkaitan dengan keterbatasan fungsional sebagaimana yang direkomendasikan oleh American Diabetes Association (ADA) ${ }^{5}$, bahwa target pencapaian $\mathrm{HBA} 1 \mathrm{C}<7 \%$ untuk mengurangi risiko komplikasi makrovaskular maupun mikrovaskular. Hal tersebut menjadi salah satu faktor pasien mengalami distress. Diabetes distress merupakan kondisi yang dimanifestasikan sebagai perasaan khawatir, frustasi, dan keputusasaan ${ }^{4}$. Respon emosi negatif ini muncul akibat tingginya kebutuhan komitmen yang harus dijalankan oleh pasien diabetes, dan respon ini berbeda dengan respon yang ditunjukkan oleh pasien dengan major depressive disorder (MDD) ${ }^{6}$.
Penelitian sebelumnya memaparkan bahwa pasien DM yang menjalani pengobatan insulin, secara signifikan berisiko mengalami diabetes distress jika dibandingkan dengan pasien yang tidak menjalani regimen pengobatan insulin ${ }^{7}$. Sejauh pengetahuan peneliti, kajian literatur terkait respon emosi negatif pada pasien diabetes masih berfokus pada kejadian depresi, gejala depresi, dan kecemasan jika dibandingkan dengan distress diabetes, padahal kejadian distress diabetes di tatanan klinis cukup tinggi yaitu sekitar 18\%-45\% pada pasien diabetes. Tanenbaum, Kane, Kenowitz, dan Gonzalez ${ }^{7}$ menyatakan bahwa diabetes distressberhubungan dengan buruknya perilaku manajemen diri pasien serta outcome perawatan penyakit pasien.

Data di tiga rumah sakit yang menjadi lokasi penelitian, yaitu RS PKU Muhammadiyah Yogyakarta, RSU PKU Muhammadiyah Bantul, dan RSUD Panembahan Senopati, diperoleh hasil bahwa DM merupakan lima besar penyakit tertinggi di ketiga RS pada tahun 2016. Saat dilakukan pemeriksaan pada 5 pasien DM yang dirawat inap di ketiga RS tersebut, didapatkan 4 pasien (80\%) mengalami distress, yang ditandai dengan adanya perasaan putus asa, cemas akan pembiayaan pengobatan, perasaan frustasi akibat glukosa darah dan tekanan darah yang tidak terkontrol, serta takut akan ancaman terjadinya komplikasi lanjutan dari DM.

Dari latar belakang yang telah diuraikan diatas, maka dapat diketahui bahwa kejadian diabetes distress merupakan salah satu masalah mayor yang mungkin dialami oleh pasien DM dan belum mendapatkan perhatian yang optimal. Oleh karena itu tujuan dari penelitian ini adalah untuk mengidentifikasi faktor karakteristik demografi yang berhubungan dengan distress pada pasien diabetes tipe 2 di Yogyakarta, meliputi variabel usia, jenis kelamin, tingkat pendidikan, komorbiditas, serta lama menderita diabetes. Hasil dari penelitian ini kemudian akan didalami lebih lanjut sampai pada prencanaan intervensi yang cocok untuk pencegahan atau pengelolaan diabetes distress. 


\section{Metode}

\section{Prosedur Penelitian}

Jenis penelitian ini adalah deskriptif analitik untuk mengetahui faktor-faktor yang berhubungan dengan kejadian distress pada pasien diabetes tipe 2. Penelitian ini menggunakan pendekatan kuantitatif dengan rancangan cross-sectional. Penelitian ini akan dilakukan di tiga rumah sakit, yaitu RSU PKU Muhammadiyah Yogyakarta, RSU PKU Muhammadiyah Bantul, serta RSUD Panembahan Senopati Bantul pada Bulan November 2017 hingga Mei 2018.

Penelitian ini menggunakan lima variabel bebas: 1) Usia, yang dikategorikan menjadi 2, yaitu kelompok usia 19-59 tahun dan $\geq 60$ tahun; 2) Jenis kelamin, dikategorikan menjadi laki-laki dan perempuan; 3) Tingkat pendidikan, dikategorikan menjadi pendidikan dasar awal (SD dan SMP) dan pendidikan dasar lanjut (SMA dan PT); 4) Durasi penyakit, dikategorikan menjadi $\leq 5$ tahun dan $>5$ tahun; serta 5) komorbid,dikategorikan menjadi ada atau tidak ada komorbid. Variabel terikat dalam penelitian ini adalah distress diabetes.

Analisis regresi logistik digunakan untuk mengetahui hubungan sebab-akibat dengan menentukan nilai $Y$ (sebagai variabel dependen) dan untuk menaksir nilai-nilai yang berhubungan dengan $X$ (sebagai variabel independen) pada penelitian dengan variabel yang menggunakan skala data nominal. Regresi logistik pada penelitian ini menggunakan metode backward, dengan 6 step. Pada step ke 6 didapatkan variabel yang paling berhubungan dengan kejadian diabetes distress.

\section{Populasi dan Sampel}

Pengambilan sampel dilakukan menggunakan teknik accidental sampling melibatkan pasien diabetes tipe II dengan kriteria usia > 18 tahun, compos mentis, dan tidak dalam kondisi gawat darurat. Dari 48 kuesioner yang terkumpul hanya diolah 32 kuesioner karena terdapat data yang kurang lengkap.

\section{Instrumen Penelitian}

Data diperoleh menggunakan dua buah instrumen penelitian. Instrumen karakteristik demografi pasien dibuat sendiri oleh peneliti meliputi identitas responden, usia, jenis kelamin, tingkat pendidikan, durasi diabetes serta ada tidaknya komorbiditas. Instrumen Distress Diabetes Scale 17 (DDS17) digunakan untuk mengidentifikasi distress pada pasien diabetes. Apabila rata-rata responden menunjukkan nilai 2.0 sampai 2.9 maka diinterpretasikan kesulitan yang dialami penderita diabetes berada pada tingkat sedang, sedangkan apabila nilai rata-rata responden menunjukkan nilai $\geq 3.0$ maka diinterpretasikan kesulitan yang dialami penderita diabetes berada pada tingkat tinggi ${ }^{8}$.

\section{Hasil \& Pembahasan}

Fisher, Mullan, Skaff, Glasgow, Arean dan Hessler $^{9}$ menyatakan bahwa diabetes distress merupakan gejala non-psikiatri yang sangat sering

Tabel 1 | Distribusi frekuensi karakteristik responden Diabetes Tipe II di Ruang Rawat Inap RSU PKU Muhammadiyah Yogyakarta, RSU PKU Muhammadiyah Bantul, serta RSUD Panembahan Senopati Bantul $(n=32)$

Karakteristik

N $\%$

Usia Responden

\begin{tabular}{lll}
$19-59$ tahun & 13 & 40,6 \\
$\geq 60$ tahun & 19 & 59,4 \\
\hline Total & 32 & 100
\end{tabular}

Jenis Kelamin

\begin{tabular}{|lll|}
\hline Laki-laki & 11 & 34,4 \\
\hline Perempuan & 21 & 65,6 \\
\hline Total & 32 & 100 \\
\hline
\end{tabular}

Tingkat Pendidikan

Pendidikan dasar $12 \quad 37,5$

awal (SD, SMP)

Pendidikan dasar $20 \quad 62,5$ lanjut (SMA, PT)

Total $\quad 32 \quad 100$

\section{Lama Menderita} Diabaetes

\begin{tabular}{|lll|}
\hline$\leq 5$ tahun & 12 & 37,5 \\
\hline$>5$ tahun & 20 & 62,5 \\
\hline Total & 32 & 100 \\
\hline
\end{tabular}

Komorbid

\begin{tabular}{|c|c|c|}
\hline Ada komorbid & 27 & 84,4 \\
\hline $\begin{array}{l}\text { Tidak ada } \\
\text { komorbid }\end{array}$ & 5 & 15,6 \\
\hline Total & 32 & 100 \\
\hline
\end{tabular}


Tabel 2 | Kategori distress pada responden Diabetes Tipe II di Ruang Rawat Inap RSU PKU Muhammadiyah Yogyakarta, RSU PKU Muhammadiyah Bantul, serta RSUD Panembahan Senopati Bantul $(n=32)$

\begin{tabular}{r|cc} 
Kategori Distress & N & $\%$ \\
\hline Distress ringan & 22 & 68,8 \\
Distress sedang & 10 & 31,3 \\
Distress berat & 0 & 0 \\
Total & 32 & 100
\end{tabular}

terjadi pada pasien diabates sehingga hal tersebut diasumsikan sebagai bagian dari penyakit tersebut. Diabetes distres ini juga diasumsikan sebagai salah satu prediktor baik buruknya perawatan diri yang dilakukan pasien, serta terkontrolnya kadar glukosa darah pada pasien. Hasil penelitian ini menunjukkan bahwa sebanyak $68,8 \%$ pasien diabetes mengalami distress dalam kategori ringan, dan 31,3\% termasuk pada kategori distress sedang, dan tidak ada pasien yang mengalami distress berat (0\%) (Tabel 2)

Tabel 3 | Faktor yang berhubungan dengan distress pada responden Diabetes Tipe II di Ruang Rawat Inap RSU PKU Muhammadiyah Yogyakarta, RSU PKU Muhammadiyah Bantul, serta RSUD Panembahan Senopati Bantul ( $n=32$ )

B S.E. Wald df Sig. $\quad \operatorname{Exp}(B) \quad 95 \%$ C.I.for $\operatorname{EXP}(B)$

\begin{tabular}{|c|c|c|c|c|c|c|c|c|c|}
\hline & & & & & & & \\
\hline & & & & & & & & Lower & Upper \\
\hline \multirow{6}{*}{ Step 1} & Usia(1) & .187 & .878 & .045 & 1 & .832 & 1.205 & .216 & 6.738 \\
\hline & Jenis Kelamin(1) & .457 & .908 & .253 & 1 & .615 & 1.579 & .266 & 9.353 \\
\hline & Pendidikan(1) & 1.187 & .936 & 1.609 & 1 & .205 & 3.278 & .523 & 20.533 \\
\hline & Lama Menderita(1) & -.952 & .951 & 1.004 & 1 & .316 & .386 & .060 & 2.486 \\
\hline & Comorbide(1) & -1.018 & 1.281 & .631 & 1 & .427 & .361 & .029 & 4.452 \\
\hline & Constant & -1.047 & .729 & 2.059 & 1 & .151 & .351 & & \\
\hline \multirow{5}{*}{ Step 2} & Jenis_Kelamin(1) & .527 & .846 & .388 & 1 & .533 & 1.693 & .323 & 8.883 \\
\hline & Pendidikan(1) & 1.240 & .906 & 1.871 & 1 & .171 & 3.455 & .585 & 20.419 \\
\hline & Lama_menderita(1) & -.981 & .941 & 1.087 & 1 & .297 & .375 & .059 & 2.371 \\
\hline & Comorbide(1) & -1.019 & 1.275 & .639 & 1 & .424 & .361 & .030 & 4.393 \\
\hline & Constant & -1.002 & .698 & 2.060 & 1 & .151 & .367 & & \\
\hline \multirow{4}{*}{ Step 3} & Pendidikan(1) & 1.140 & .883 & 1.667 & 1 & .197 & 3.127 & .554 & 17.644 \\
\hline & Lama_menderita(1) & -.996 & .929 & 1.149 & 1 & .284 & .369 & .060 & 2.283 \\
\hline & Comorbide(1) & -.934 & 1.234 & .574 & 1 & .449 & .393 & .035 & 4.408 \\
\hline & Constant & -.767 & .572 & 1.801 & 1 & .180 & .464 & & \\
\hline \multirow{3}{*}{ Step 4} & Pendidikan(1) & 1.081 & .871 & 1.543 & 1 & .214 & 2.949 & .535 & 16.244 \\
\hline & Lama_menderita(1) & -.887 & .915 & .940 & 1 & .332 & .412 & .069 & 2.474 \\
\hline & Constant & -.914 & .543 & 2.831 & 1 & .092 & .401 & & \\
\hline \multirow{2}{*}{ Step 5} & Pendidikan(1) & .762 & .781 & .953 & 1 & .329 & 2.143 & .464 & 9.898 \\
\hline & Constant & -1.099 & .516 & 4.526 & 1 & .033 & .333 & & \\
\hline Step 6 & Constant & -.788 & .381 & 4.274 & 1 & .039 & .455 & & \\
\hline
\end{tabular}

a. Variable(s) entered on step 1: usia, Jenis_Kelamin, Pendidikan, Lama_menderita, Comorbide. 
Tabel 4 | Faktor yang paling berhubungan dengan distress pada responden Diabetes Tipe II di Ruang Rawat Inap RSU PKU Muhammadiyah Yogyakarta, RSU PKU Muhammadiyah Bantul, serta RSUD Panembahan Senopati Bantul ( $n=32)$

\begin{tabular}{|c|c|c|c|c|c|c|c|c|c|c|}
\hline \multirow{3}{*}{$\begin{array}{c}\text { Variabel } \\
\text { Pendidikan }\end{array}$} & \multicolumn{4}{|c|}{ Diabetes Distress } & \multirow{2}{*}{\multicolumn{2}{|c|}{ Total }} & \multirow{3}{*}{$\operatorname{Exp}(B)$} & \multirow{2}{*}{\multicolumn{2}{|c|}{$95 \% \mathrm{Cl}$ for $\operatorname{Exp}(\mathrm{B})$}} & \multirow{3}{*}{ Nilai $p$} \\
\hline & \multicolumn{2}{|c|}{ Rendah } & \multicolumn{2}{|c|}{ Sedang } & & & & & & \\
\hline & $N$ & $\%$ & $N$ & $\%$ & $\mathrm{~N}$ & $\%$ & & Lower & Upper & \\
\hline $\begin{array}{l}\text { Pendidikan } \\
\text { dasar awal }\end{array}$ & 7 & 21 & 5 & 15 & 12 & 37 & & & & \\
\hline $\begin{array}{l}\text { Pendidikan } \\
\text { dasar lanjut }\end{array}$ & 15 & 46 & 5 & 15 & 20 & 62 & 2,143 & 0,464 & 9,898 & 0,039 \\
\hline Total & 22 & 68 & 10 & 31 & 32 & 100 & & & & \\
\hline
\end{tabular}

Berdasarkan tabel 1 dapat diketahui bahwa distribusi pasien dengan diabetes tipe 2 paling banyak pada kategori usia $\geq 60$ tahun $(59,4 \%)$ diikuti dengan kelompok usia 19-59 tahun (40,6\%). Kirkman et al., (2012) menyatakan bahwa berkembangnya diabetes pada populasi lanjut usia dikarenakan mekanisme peningkatan resistensi insulin serta rusaknya fungsi sel islet pada pankreas seiring dengan proses degeneratif. Munculnya risiko distress pada pasien diabetes lanjut usia juga disebabkan karena tingginya kejadian amputasi pada ekstremitas bawah, berkembangnya myocardial infark, gangguan visual, serta komplikasi gagal ginjal kronik ${ }^{10}$.

Berdasarkan Tabel 1, diketahui bahwa sebagian besar responden didominasi oleh perempuan $(65,6 \%)$ dan sisanya laki-laki (34,4\%). Hasil penelitian sebelumnya menyatakan bahwa terdapat kenaikan tajam prevalensi diabetes mellitus tipe 2 (T2DM) sejalan dengan semakin banyaknya bukti perbedaan jenis kelamin. T2DM lebih sering didiagnosis pada laki-laki dengan usia produktif, dan perempuan dengan obesitas. stres psikologis memberikan dampak yang lebih besar pada wanita daripada laki-laki ${ }^{10}$.

Tabel 1 juga menunjukkan bahwa sebagian besar responden sudah menderita diabetes $>5$ tahun $(62,5 \%)$ dan sisanya menderita diabetes $<5$ tahun $(37,5 \%)$. Faktor risiko yang meningkatkan kejadian distres tersebut salah satunya adalah durasi penyakit yang lama. Potensi komplikasi dibetes seperti tingginya kadar glukosa darah, maupun keharusan melakukan regimen terapi seperti kontrol glukosa darah, penggunaan insulin dalam jangka panjang, serta rendahnya dukungan dan motivasi mampu menyebabkan distress ${ }^{11}$.

Selain itu sebagian besar responden sudah menderita diabetes $>5$ tahun (84,4\%). Adriaanse et al., ${ }^{12}$ menyatakan bahwa komorbid dan diabetes distres menjadi dua faktor yang saling mempengaruhi. Gangguan pada metabolisme glukosa dikaitkan dengan peningkatan gejala distres, begitu pula sebaliknya, munculnya distress pada pasien T2DM menyebabkan tingginya kadar glukosa darah.

Pada variabel tingkat pendidikan, sebagian besar responden berada pada tingkat pendidikan dasar lanjut (62,5\%) dan sisanya pada tingkat pendidikan dasar awal (37,5\%) (Tabel 4). Sacerdote et al., ${ }^{13}$ menyatakan bahwa dibandingkan dengan responden dengan tingkat pendidikan tinggi, responden dengan tingkat pendidikan rendah memiliki risiko lebih tinggi mengalami T2DM [HR: 1,77, 95\% confidence interval (Cl): 1,69-1,85; Ptrend $<0,01]$. pasien dengan tingkat pendidikan yang lebih rendah berisiko 2,143 kali mengalami diabetes distress [Exp(B): 2,143]. Menurut Agardh, et al., ${ }^{14}$ rendahnya tingkat pendidikan berhubungan dengan burden diabetes pada pria sebesar $17,2 \%(7,9 \%-26,2 \%)$, dan pada wanita sebesar $20,1 \%(7,6 \%-33,8 \%)$.

Hal tersebut sesuai dengan hasil penelitian ini bahwa tingkat pendidikan menjadi variabel yang paling berhubungan dengan diabetes distress [95\% confidence interval (Cl): 0,464-9,898; $\mathrm{p}=0,039]$. Tingginya burden diabetes pada pasien dengan pendidikan yang lebih rendah karena pasien harus beradaptasi untuk melakukan regimen terapi dalam mengelola penyakitnya seperti manejemen 
diet, aktivitas fisik, pengelolaan kadar glukosa darah, pencegahan dan penanganan hipoglikemia, dan lain-lain. Rendahnya tingkat pendidikan dikaitkan dengan rendahnya pula kemampuan seseorang untuk menguasai keterampilan tertentu ${ }^{15}$.

Implikasi lebih lanjut untuk menyikapi temuan dalam penelitian ini adalah perawat mampu menyediakan media edukasi bagi pasien dengan mempertimbangkan tingkat pendidikan pasien. Media edukasi dapat berupa buklet bergambar yang dimaksudkan untuk memudahkan visualisasi pasien sehingga mampu meningkatkan pemahaman pasien.

\section{Kesimpulan}

Kategori diabetes distress pada penelitian ini yaitu sebesar $68,8 \%$ pasien mengalami distress ringan dan $31,3 \%$ pasien mengalami distres sedang. Tidak ada pasien dengan distress berat. Variabel tingkat pendidikan menjadi faktor yang paling berhubungan dengan kejadian diabetes distress $(p=0,039)$. Pasien diabetes dengan pendidikan yang lebih rendah beresiko 2,143 kali lipat mengalami diabetes distress [Exp(B): 2,143)].

\section{Apresiasi}

Penelitian ini merupakan penelitian hibah yang diperoleh dari Direktorat Riset dan Pengabdian Masyarakat Kementerian Riset, Teknologi, dan Pendidikan Tinggi pada tahun 2017.

\section{Konflik Kepentingan}

Tidak ada konflik kepentingan apapun dalam penelitian ini.

\section{Bibliografi}

1. Jannoo, Z., Wahb, Y. B., Lazim, A. M., dan Hassali, M. A. 2017. Examining diabetes distress, medication adherence, diabetes self-care activities, diabetesspecific quality of life and health-related quality of life among type 2 diabetes mellitus patients. Journal of Clinical \& Translational Endocrinology. Vol. 9, 48-54.

2. Riset Kesehatan Dasar (RISKESDAS). 2013. Riset Kesehatan Dasar 2013. http://www.depkes.go.id/ resources/download/general/Hasil\%20Riskesdas $\% 20$ 2013.pdf
3. Hyder, O., Mirghani, M. D. 2017. Distress and psychopathology among Sudanese patients with type 2 diabetes mellitus and its relation to glycaemic control. Journal of Taibah University Medical Sciences. No. 12. Vol. 4, 298-303.

4. Gariepy, G., Smith, K. J., Schmitz, N. 2013. Diabetes distress and neighborhood characteristics in people with type 2 diabetes. Journal of Psychosomatic Research. Vol. 75. 147-152.

5. American Diabetes Assosiation. 2014. A1C and eAG. http://www.diabetes.org/living-with-diabetes/ treatment-and-care/blood-glucose-control/a1 c/?loc= Iwd-slabnav

6. Lee, J., Lee, E-H., Kim, C-J., Moond, S. H. (2015). Diabetes-related emotional distress instruments: A systematic review of measurement properties. International Journal of Nursing Studies. Vol. 52. 1868-1878

7. Tanenbaum, M. L., Kane, N. S., Kenowitz, J., Gonzalez, J. S. 2016. Diabetes distress from the patient's perspective: Qualitative themes and treatment regimen differences among adults with type 2 diabetes. Journal of Diabetes and Its Complications. Vol. 30. 1060-1068.

8. Arifin, B., Perwitasari, D. A., AtThobari, J., Cao, Q., Krabbe, P. F. M., Postma, M. J. 2017. Translation, Revision, and Validation of the Diabetes Distress Scale for Indonesian Type 2 Diabetic Outpatients with Various Types of Complications. Value in Health Regional Issues. Vol. 12c. 63-7 3.

9. Fisher L, Mullan J. T., Skaff, M. M., Glasgow, R. E., Arean P., Hessler, D. 2009. Predicting diabetes distress in patients with type 2 diabetes: a longitudinal study. Diabetes Medicine, Vol. 26, 622-627.

10. Kirkman, M. S., Briscoe, V. J., Clark, N., Florez, H., Haas, L. B., Halter, J. B., Huang, E. S., et al. 2012. Diabetes in Older Adults. Diabetes Care. No. 35, Vol. 12, 2650-2664.

11. Sturt, J. 2018. Diabetes distress: how to detect and manage it within the diabetes care team. https://www.kcl.ac.uk/nursing/research/PolicyPlus\%2 0and\%20PracticePlus/Practice-Issue-3---Online.pdf

12. Adriaanse, M. C., Pouwer, F., Dekker, J. M., Nijpels, G., Stehouwer, C. D., Heine, R. J., Snoek, F. J. 2008. Diabetes-Related Symptom Distress in Association With Glucose Metabolism and Comorbidity. Diabetes Care.. No.31, Vol.12, 2268-2270.

13. Sacerdote C., Ricceri F., Rolandsson O., Baldi I., Chirlaque M. D., Feskens E., Bendinelli B., Ardanaz E., et al. 2012. Lower educational level is a predictor of incident type 2 diabetes in European countries: the EPIC-InterAct study. International Journal of Epidemiology. No. 41, Vol.4, 1162-73. 
14. Agardh, E., Sidorchuk, A., Hallqvist, J., Ljung, R., Peterson, S., Moradi, T., Allebeck, P. 2011. Burden of type 2 diabetes attributed to lower educational levels in Sweden. Population Health Metrics, No.9, Vol. 60

15. Dalgard, O. S., Mykletun, A., Rognerud, M., Johansen, R., Zahl, P. H. 2007. Education, sense of mastery and mental health: results from anation wide health monitoring study in Norway. BMC Psychiatry. No.7, Vol. 20. 